\title{
Primary Retinal Targets in the Atlantic Loggerhead Sea Turtle, Caretta caretta
}

\author{
Andrew H. Bass* and R. Glenn Northcutt \\ Division of Biological Sciences University of Michigan Ann Arbor, Michigan, USA
}

\begin{abstract}
Summary. Autoradiographic analysis distinguished twelve primary retinal targets in the diencephalon and the mesencephalon of the Atlantic loggerhead sea turtle, Caretta caretta. While the majority of fibers terminate contralaterally, sparse labelling is seen over ipsilateral thalamic nuclei. The dorsal optic nucleus is the most expansive retinal target in the dorsal thalamus. Four nuclei ventral and one dorsal, to the dorsal optic nucleus, receive retinal input. Before terminating in the optic tectum, labelled fibers pass through the pretectum terminating in four nuclei. Within the superficial zone of the optic tectum, three terminal zones are recognized. A distinct accessory tegmental tract separates from the main optic tract terminating in the basal optic nucleus.

While such a multiplicity of retinal targets occurs among other reptiles, birds and mammals, it is presently impossible to accurately recognize visual homologies among amniotic vertebrates.
\end{abstract}

Key words: Sea turtles - Retinal pathways - Diencephalon

Whereas several reports describe retinofugal pathways in freshwater turtles (Kosareva 1967; Knapp and Kang 1968a, b; Hall and Ebner 1970a) no experimental studies exist for chelonid turtles. This group is of particular interest because earlier anatomical descriptions are based on the classical studies of Papez (1935) who based his analysis of the diencephalon of turtles on Chelone. The present report is the first systematic re-examination of the terminology of Papez for the diencephalon of turtles based on another chelonid turtle and the first detailed study of all primary retinofugal projections since the study of Hall and Ebner (1970a).

A preliminary summary of these results was published earlier (Bass and Northcutt 1975).

Send offprint requests to: Andrew H. Bass, Department of Ecology and Behavioral Biology, University of Minnesota, 108 Zoology Building, 318 Church Street, S.E., Minneapolis, Minnesota 55455, USA 


\section{Materials and Methods}

The animals used in this study were made available through the generosity of Dr. Archie Carr, University of Florida. Six Juvenile sea turtles (Caretta caretta) were injected with $20-40 \mu \mathrm{Ci}$ of ${ }^{3} \mathrm{H}$-proline (New England Nuclear, Boston, Massachusetts; NET 323-L-proline-2, 3-H3N). All animals were anesthetized by cold narcosis and injections were made with a $5 \mu \mathrm{l}$ Hamilton syringe through an incision in the dorsal temporal corner of the eyelid, through the scleral coat and into the vitreous body. The duration of the injection was 5-10s. Animals were maintained at a temperature of $18^{\circ} \mathrm{C}$. They were re-anesthetized with an overdose of sodium pentobarbitol at 13,24, 48, 72 and $96 \mathrm{~h}$ postoperatively, and perfused transcardially with $0.7 \%$ saline followed by AFA $(90 \mathrm{cc}$ of $80 \%$ ethanol, $5 \mathrm{cc}$ of formalin, $5 \mathrm{cc}$ of glacial acetic acid). The brains were removed from the skull, left in fixative for at least one week, and then embedded in paraffin. Subsequently, the brains were serially sectioned at $15 \mu$ in either the transverse or horizontal plane. Deparaffinized sections were coated with Kodak NTB 2 nuclear track emulsion, exposed at $7^{\circ} \mathrm{C}$ for 21 days, and then developed in Kodak D-19. All sections were counterstained with cresyl violet. Representative sections were photographed on Kodalith Orthofilm, Type 3, with a Leitz format camera and tracings of high-contrast photographs were used to chart retinal pathways and terminal fields. Terminal fields were interpreted as those regions exhibiting an increase in silver grain density over the adjacent optic tract.

Additional non-experimental material stained with cresyl violet or the Bodian method was used for cytoarchitectonic analysis.

\section{Results}

\section{Nomenclature}

Previous retinofugal studies of turtles (Kosareva 1967; Knapp and Kang 1968a, b; Hall and Ebner 1970a) use the nomenclature of Papez (1935) and/or Huber and Crosby (1926) to describe the diencephalon and the mesencephalon. The majority of studies of the diencephalon, and of retinofugal pathways, in a variety of reptiles (Senn 1968; Butler and Northcutt 1971, 1973, 1978; Repérant 1973a; Cruce and Cruce 1978; Repérant et al. 1978) utilize a nomenclature that is essentially that of Kuhlenbeck (1931). Since the number and topography of retinal targets in Caretta compares closely to those of the latter studies, we employ the nomenclature of Butler and Northcutt (1973) as adapted from Kuhlenbeck (1931) and Senn (1968) to facilitate future phyletic comparisons.

Abbreviations. $A T$ Area triangularis; $A V$ Area ventralis; BON Basal optic nucleus; BOT Basal optic tract; $C$ Central gray zone of the optic tectum; $D C$ Dorsal central nucleus; $D C X$ Dorsal cortex; $D L$ Nucleus dorsolateralis; $D M$ Nucleus dorsomedialis; $D O N$ Dorsal optic nucleus; $D P$ Nucleus dorsalis pretectalis; $D V R$ Dorsal ventricular ridge; $E$ Entopeduncular nucleus; $G L V$ Ventral geniculate nucleus; $G P$ Nucleus geniculatus pretectalis; $H$ Nucleus habenularis; $H L$ Nucleus habenularis lateralis; $H M$ Nucleus habenularis medialis; $L C$ Lateral cortex; $L F B$ Lateral Forebrain bundle; $L M$ Nucleus lentiformis mesencephali; $L P$ Lateral preoptic nucleus; $M C$ Medial cortex; $M F B$ Medial forebrain bundle; $M P$ Medial preoptic nucleus; $M P o$ Nucleus medialis posterior; $N f$ Nucleus of the medial longitudinal fasciculus; $N i$ Nucleus interstitialis of the medial longitudinal fasciculus; $O C$ Optic chiasm; $O N$ Optic nerve; $O T$ Optic tract; $P$ Nucleus posterodorsalis; $P D$ Pars dorsalis of the lateral geniculate nucleus; Pe External pretectal nucleus; $P G$ Periventricular gray zone of the optic tectum; $P H$ Nucleus periventricularis hypothalami; $p l$ Lateral segment of the dorsal optic nucleus; $P M$ Nucleus profundus mesencephali; $p m$ Medial segment of the dorsal optic nucleus; $P P$ Periventricular preoptic nucleus; $p p$ Pars plicata of nucleus lentiformis thalami; $R$ Nucleus rotundus; $R e$ Nucleus reuniens; $R U$ Nucleus ruber; $S$ Superficial zone of the optic tectum; $s$ stria medullaris; $S C$ Nucleus suprachiasmaticus; $S O$ Subcommissural organ; TeO Optic tectum; $V L$ Nucleus ventrolateralis; $V L d$ Pars dorsalis of nucleus ventrolateralis; $V L v$ Pars ventralis of nucleus ventrolateralis; $V M$ Nucleus ventromedialis; $V P$ Nucleus ventralis pretectalis 

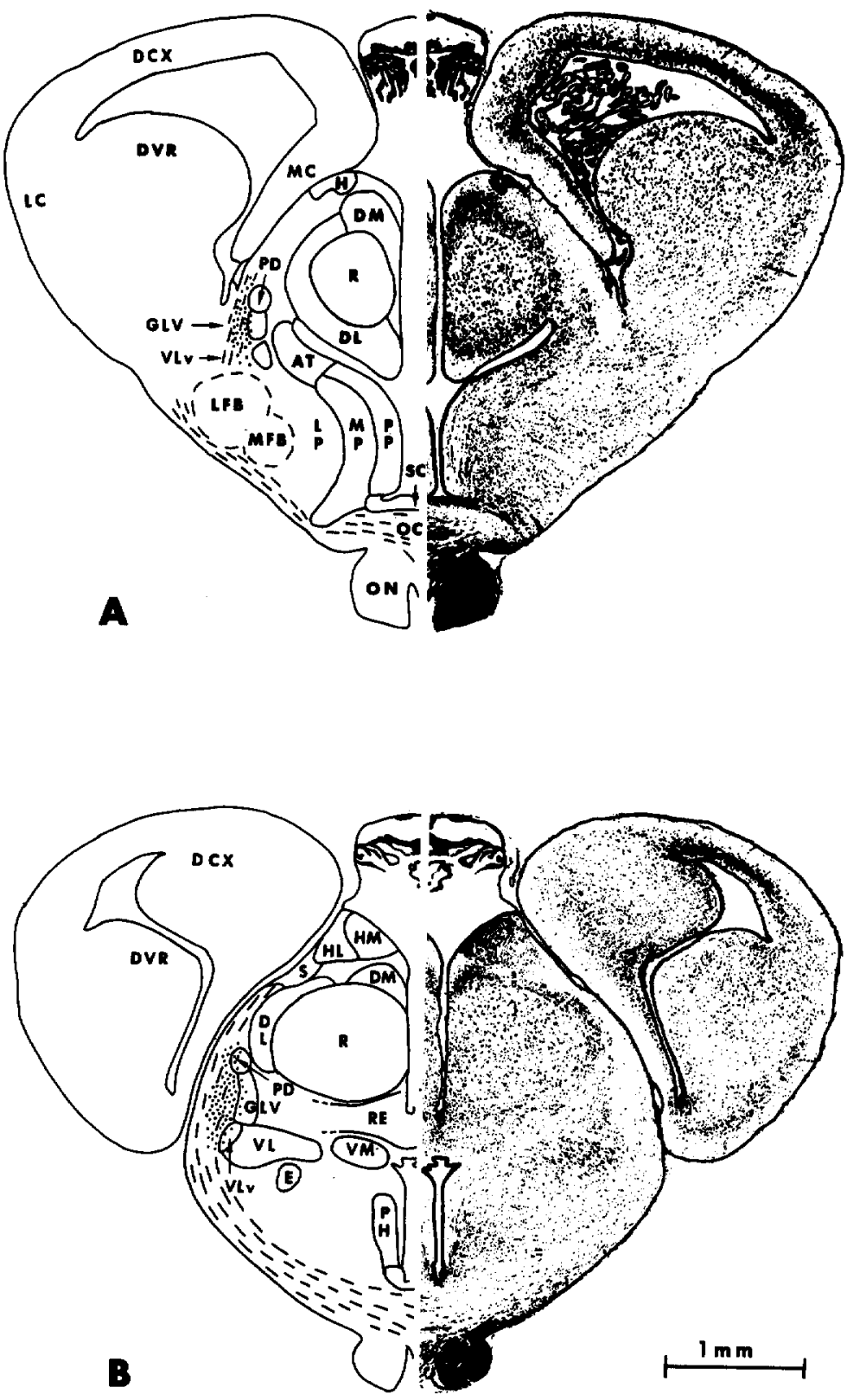

Fig. 1. Transverse sections through the diencephalon of Caretta caretta. In this Fig. and Figs. 2 and 3 , a Nissl photomicrograph appears on the right with chartings of the contralateral retinal projections on the left. Terminals are indicated with stippling and fibers with dashes. A Transverse section through the rostral pole of the pars dorsalis of the lateral geniculate nucleus $(P D)$. B Transverse sections through the caudal pole of $P D$ 


\section{Experimental Results}

Labelled optic fibers (dashes, Figs. 1-3) course caudally within the optic nerve (ON, Fig. 1A) and decussate incompletely at the optic chiasm (OC, Fig. 1A). Within the hypothalamus, fibers pass ventral to the nucleus suprachiasmaticus (SC, Fig. 1A) and ventrolateral to the medial and lateral preoptic nuclei (MP, LP: Fig. 1A). In no region of the hypothalamus is the silver grain density greater than that in the adjacent optic tract. However, hypothalamic nuclei may receive retinal input if their dendrites extend laterally intercepting retinal efferents.

Optic fibers continue caudally along the ventrolateral surface of the diencephalon terminating (stippling, Figs. 1-3) in the rostrolateral thalamus. The pars dorsalis of the lateral geniculate nucleus (PD, Fig. 1 A, B) is the most rostral thalamic target. There is not a distinct boundary between the lateral neuropil and medial cell plate of the pars dorsalis.

Retinal fibers terminate in a second diffuse neuropil region lateral to the cell plate of the ventral geniculate nucleus (GLV, Fig. 1A, B; 2A, B). The ventral geniculate continues caudally to rostral pretectal levels as a retinal target (Fig. 2B), while the pars dorsalis of the lateral geniculate drops out at mid-thalamic levels (Fig. 2A).

A nonretinal-recipient zone - area triangularis (AT, Fig. 1A) - lies just medial to the ventral geniculate nucleus. Area triangularis is replaced caudally by a nonretinal-recipient nucleus ventromedialis (VM, Fig. 1B, 2A) - and a retinalrecipient nucleus - nucleus ventrolateralis (VL, Fig. 1 B, 2A). A rostral extension of the ventral retinal-recipient zone (pars ventralis) of nucleus ventrolateralis (VLv, Fig. 1A) appears lateral to area triangularis. Caudally, as a more well-defined nucleus ventrolateralis extends medially, the pars ventralis of nucleus ventrolateralis continues to receive retinal input (Figs. 1B, 2A).

The largest retinal-recipient zone in the dorsal thalamus is the dorsal optic nucleus (DON, Fig. 2A, B). Appearing as a caudal and lateral extension of nucleus dorsolateralis (DL, Fig. 1A, B), the dorsal optic nucleus consists of a medial non retinal-recipient zone (pm, Fig. 2A) and a lateral retinal-recipient zone (pl, Fig. 2A). While the medial zone appears continuous rostrally with nucleus dorsolateralis, the lateral zone expands caudally to occupy a large region along the lateral thalamic wall. Dense grain deposits occur over the lateral neuropil, while small grain clumps often appear adjacent to the medially placed cell bodies (Fig. 2A, B; 4A).

As the dorsal optic nucleus expands laterally, retinal fibers pass ventral and medial terminating within a restricted dorsal zone (pars dorsalis) of nucleus ventrolateralis (VLd, Fig. 2A). At this same level, the pars ventralis of nucleus ventrolateralis and the ventral geniculate nucleus are displaced medially, both continuing to receive retinal input.

Finally, labelled fibers pass dorsal and medial to the dorsal optic nucleus, terminating in the dorsal central nucleus (DC, Fig. 2A, B). This diffuse aggregation of cells receives a sparser retinal input than the dorsal optic nucleus with grains also appearing over its cell bodies (Fig. 4B).

As optic fibers continue caudally toward the optic tectum, they pass through the pretectum terminating in four nuclei. Heavy grain deposits appear over two nuclei embedded within the optic tract - nucleus lentiformis mesencephali (LM, Fig. 2B) 

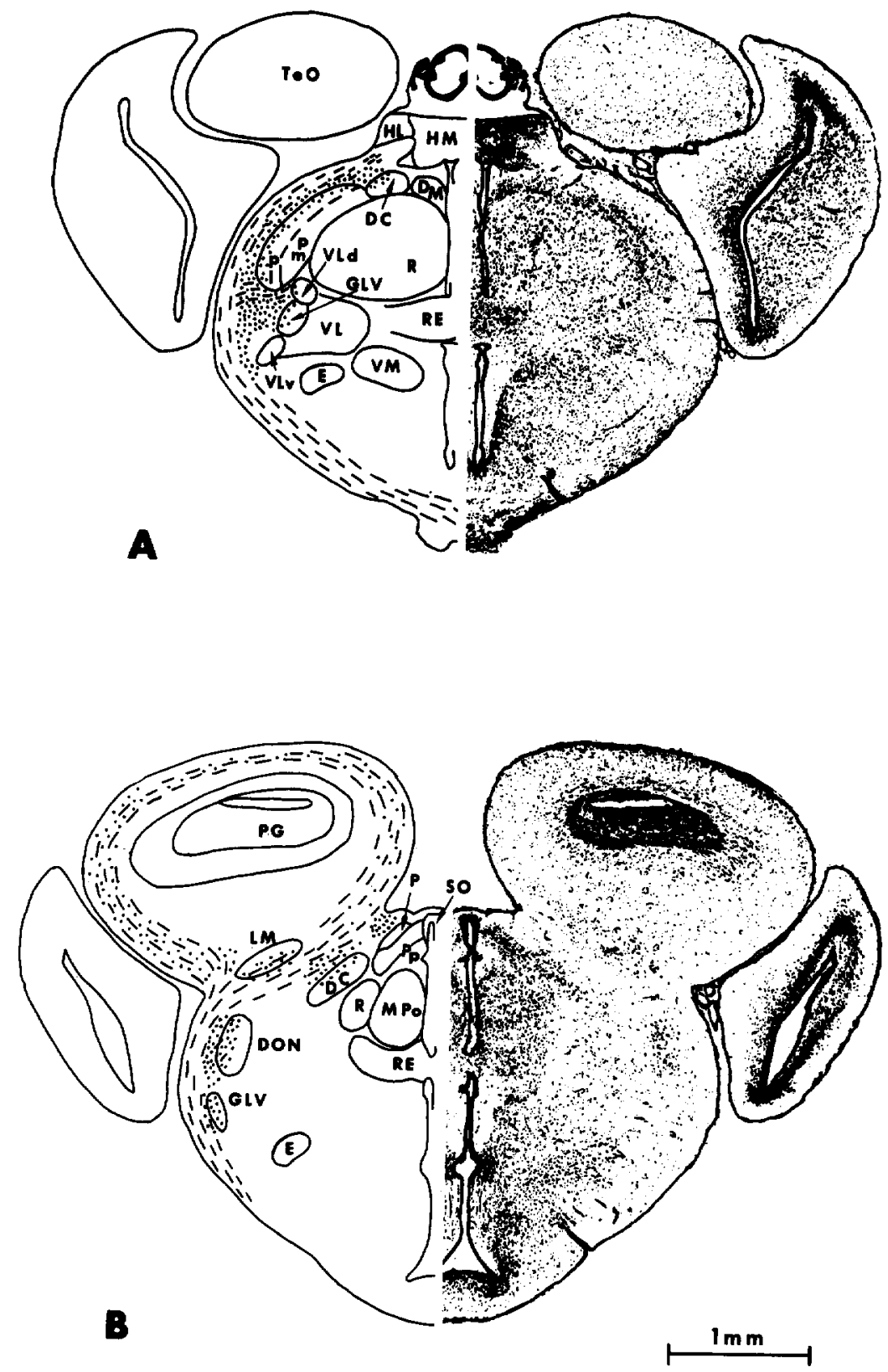

Fig. 2. A Transverse section through the lateral retinal recipient section of the dorsal optic nucleus $(p l)$, the dorsal central nucleus $(D C)$ and the pars dorsalis of nucleus ventrolateralis $(V L d)$. B Transverse section through the caudal pole of the dorsal optic nucleus $(D O N)$ and the rostral pretectum 

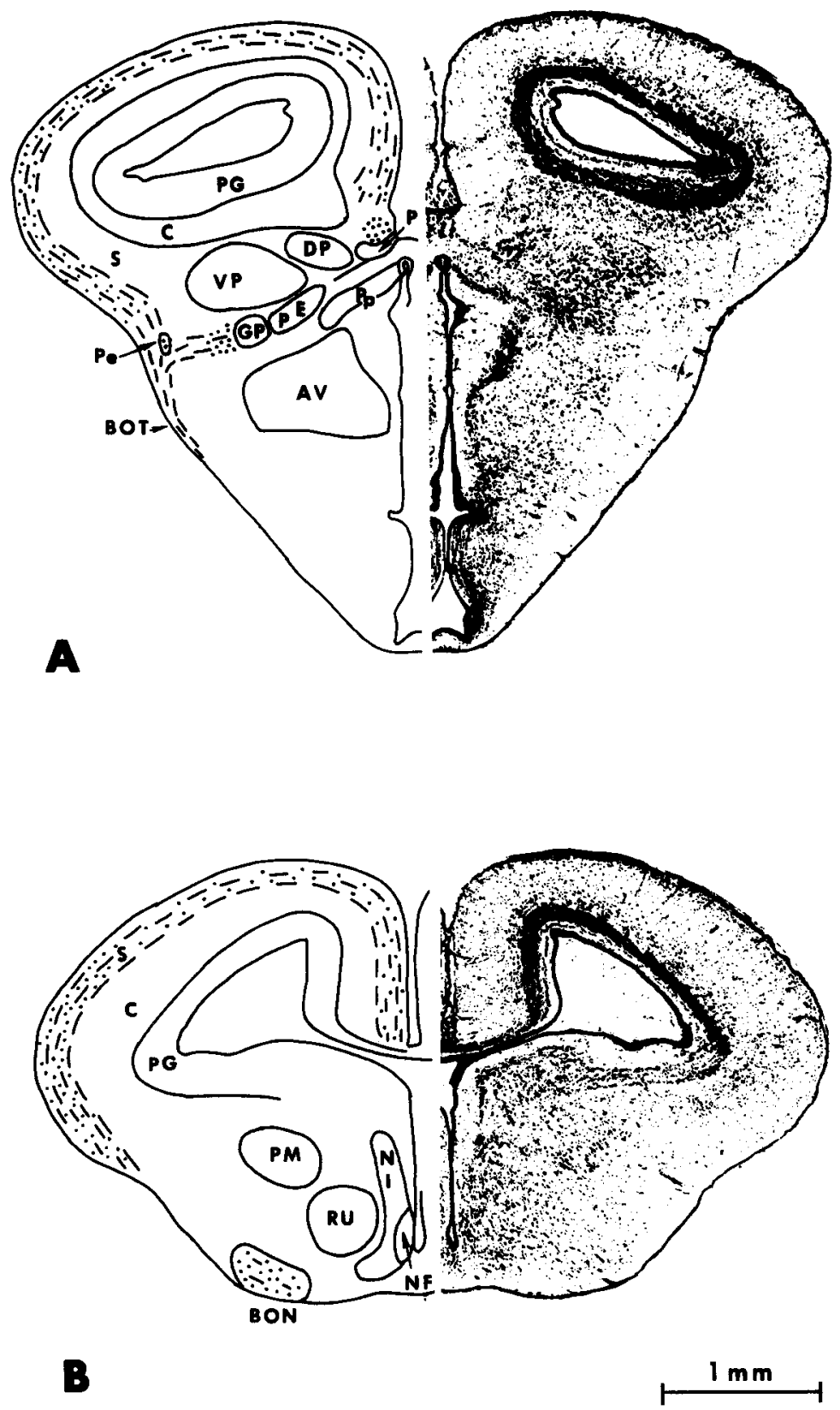

Fig. 3. A Transverse section through the caudal pretectum illustrating nucleus geniculatus pretectalis $(G P)$ and the external pretectal nucleus $(P e)$; and the superficial zone of the optic tectum $(S)$. B Transverse section through the caudal pole of the optic tectum and the basal optic nucleus $(B O N)$ 

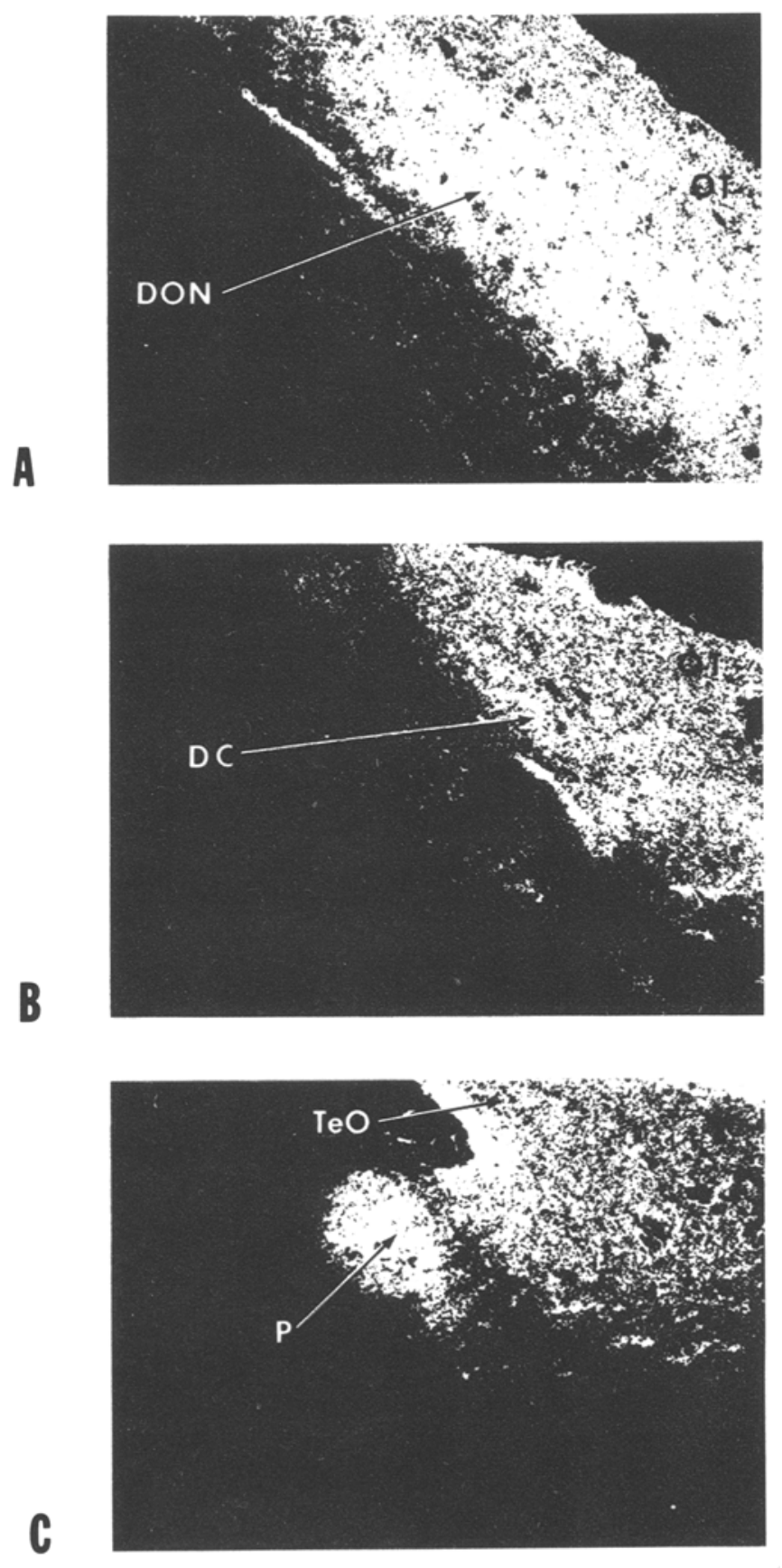

Fig. 4. Photomicrographs of retinal autoradiographs with dark field illumination. The bar scale represents $100 \mu$ for $\mathbf{A}, \mathbf{B}$ and $\mathbf{C}$. A Optic tract $(O T)$ and terminal field over the neuropil of the dorsal optic nucleus $(D O N)$. B Optic tract and neuropil of the dorsal central nucleus $(D C)$. C Nucleus posterodorsalis $(P)$ and rostral optic tectum $(\mathrm{TeO})$ 
and the external pretectal nucleus (Pe, Fig. 3A). The cells comprising the external pretectal nucleus appear to be contiguous with those of nucleus lentiformis mesencephali at mid-pretectal levels. Dense accumulations of silver grains also appear over the circular neuropil of nucleus posterodorsalis ( $\mathrm{P}$, Figs. 2B, 3A, 4C) and the lateral neuropil of nucleus geniculatus pretectalis (GP, Fig. 3A).

An accessory (basal) optic tract separates from the main optic tract at pretectal levels (BOT, Fig. 3A) and courses caudally along the ventrolateral tegmentum terminating densely within the basal optic nucleus (BON, Fig. 3B). This nucleus continues as a retinal target to the level of the exiting oculomotor nerve (not figured).

The superficial zone of the optic tectum receives a massive retinal input (S, Fig. 3A, B). In turtles, the optic tectum comprises 14 laminae; the superficial zone includes laminae 8-14 (Senn 1971). Caretta autoradiographs distinguish three terminal zones after $13 \mathrm{~h}$ survival time (horizontal plane). A dense band of grains appears just below the most superficial layer (grain-free) of the tectal roof; these two layers corresponding respectively to laminae 13 and 14. Just ventral to lamina 13 , there is a marked decrease in grains followed by a sudden increase over a broad region extending to lamina 9 . This ventral region contains a more dorsal zone of dense grains (comparable to lamina 13) followed by a more ventral zone of decreased grains. Presumably, this differental labelling is associated with optic input to lamina 12 (dorsal) and lamina 9 (ventral).

In all cases, the lateral tectal wall is more densely labelled than the medial wall. Ventral to lamina 9 there is a sharp decrease in grain density, though it is still above background counts observed in nonretinal nuclei such as nucleus rotundus. The increased grain density in the ventral tectal laminae may be due to diffusion and/or active transport of radioactive molecules, or the re-utilization of proline for protein synthesis (Heacock and Agranoff 1977).

In one animal that survived $72 \mathrm{~h}$, ipsilateral grain counts over the ventral geniculate nucleus and the pars dorsalis of the lateral geniculate nucleus are threefold higher than surrounding nonretinal nuclei.

\section{Discussion}

\section{Comparisons with Other Turtles}

The pattern of retinal targets described in the sea turtle, Caretta caretta concurs with that reported for the freshwater turtle, Chrysemys picta (Bass and Northcutt 1981). The major intergeneric differences are: (1) The pars dorsalis of the lateral geniculate nucleus is not differentiated into a distinct cell plate and lateral neuropil in Caretta, unlike Chrysemys. (2) The dorsal optic nucleus of Caretta appears to occupy a relatively greater volume of the lateral thalamus. (3) In Caretta, there is no welldefined ipsilateral retinal projections as reported for Chrysemys. While this may be a real species difference, we did not check for variance in labelling of the retinal ganglion cell layer. The possibility of ipsilateral projections in Caretta deserves further inquiry.

The number of retinal targets revealed in Caretta and Chrysemys (Bass and Northcutt 1981) compares closely to the condition in other freshwater turtles - 
Table 1. Nomenclature of Retinal Nuclei. Correspondence among terminologies applied to retinalrecipient nuclei in turtles. Kosareva (1967) is included with Papez (1935) as their nomenclatures are equivalent. All cell groups listed, except nucleus centralis lateralis (Kosareva 1967) are recognized as retinal targets. Kosareva (1967) does not identify retinal input to area pretectalis (after Papez 1935), whereas she describes the nucleus of the posterior commissure (after Papez 1935) as a pretcctal target, and the nucleus suprapeduncularis (after Papez 1935) as a medial thalamic target

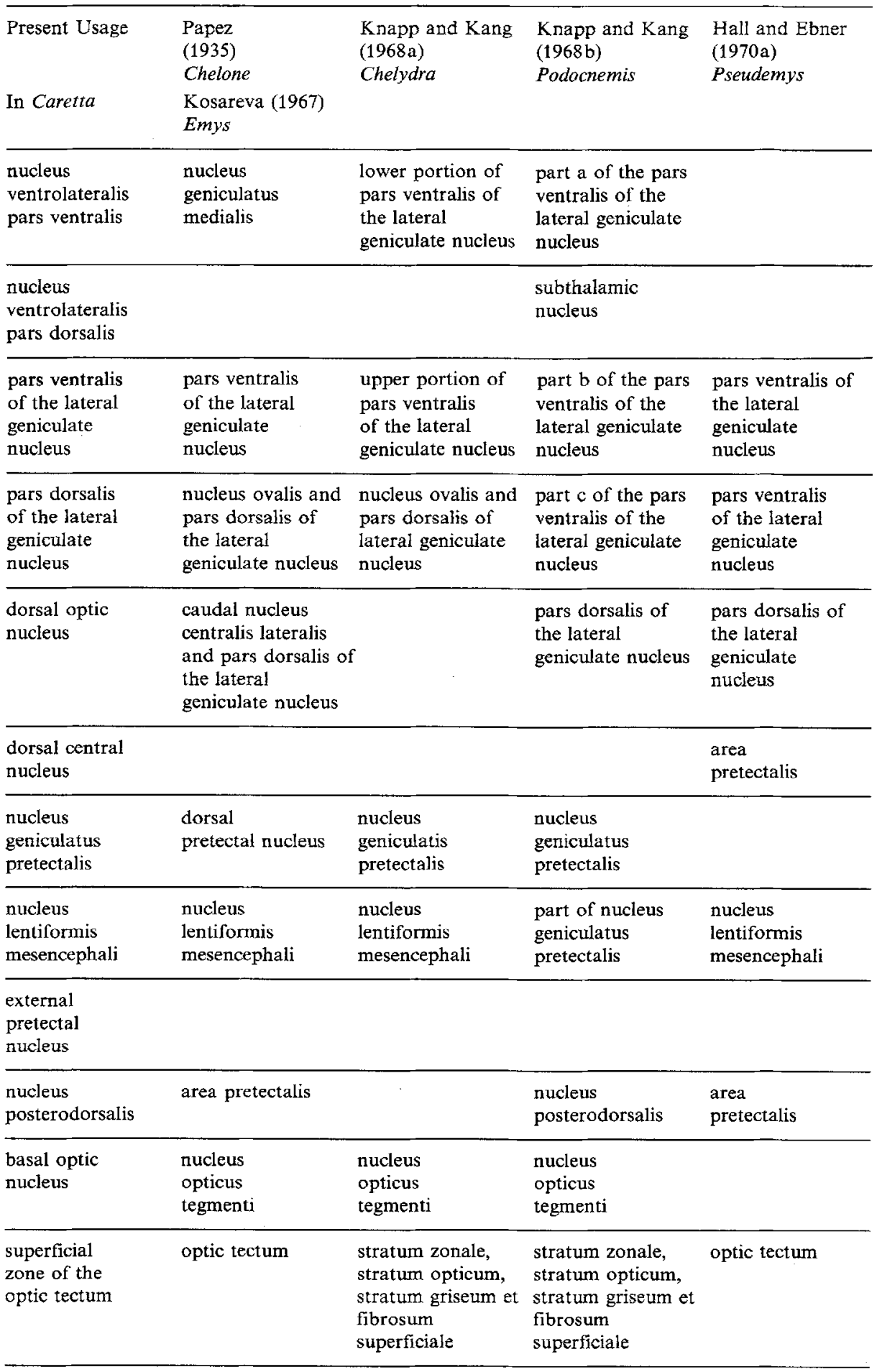


Podocnemis (Knapp and Kang 1968b), Chelydra (Knapp and Kang 1968a), and Emys (Kosareva 1967). In particular, the number and topography of thalamic targets in Caretta and Chrysemys (6 targets) compares to those of Podocnemis (5 targets, see Table 1). While Knapp and Kang (1968a) do not recognize a nucleus equivalent to our dorsal optic nucleus (Table 1), this input is revealed in autoradiographic material (A.H. Bass and R.G. Northcutt, unpublished observations). Knapp and Kang (1968a) identify a retinal-recipient nucleus ovalis in Chelydra (as Kosareva 1967), which is equivalent to a rostral segment of our pars dorsalis (Table 1 ).

For Pseudemys (Hall and Ebner 1970a) and Emys (Kosareva 1967) a lateral geniculate nucleus is identified as the primary retinal target in the lateral thalamus. As Papez (1935), these workers divide the lateral geniculate into dorsal and ventral divisions. We divide the lateral thalamic zone adjacent to the optic tract into six cell groups on the basis of differences in cell size and density, cell-free boundaries, and density of retinal terminal. These divisions compare closely with cell groups recognized in the thalamus of other reptiles (see Nomenclature), especially lizards (Butler and Northcutt 1978).

We conclude that both marine and freshwater turtles have the same number of retinal targets, although the differentiation of these targets may vary between genera.

\section{Comparisons with Other Reptiles and Birds}

Retino-hypothalamics are reported, though inconsistently, for reptiles (Knapp and Kang 1968a, b; Butler 1974; Northcutt and Butler 1974a, b; Repérant et al. 1978). In the hypothalamus of Caretta, labelled optic fibers pass ventral to preoptic neurons and further electron microscopic and/or Golgi analysis is necessary to determine if the processes of these cells intercept retinal axons.

Retinal input to the thalamus, pretectum, optic tectum and basal optic nucleus of the mesencephalic tegmentum, are commonly reported for reptiles (Butler 1974; Northcutt and Butler 1974a, b; Repérant and Rio 1976; Butler and Northcutt 1978; Repérant et al. 1978). While three or four pretectal targets are consistently recognized, the number of thalamic targets varies between two and seven. We identify six in Caretta. Comparable autoradiographic studies in two lizards, Gekko and Iguana (Butler and Northcutt 1978); the tuatara, Sphenodon (Northcutt et al. 1974); and the crocodilian, Caiman (Braford and Northcutt, in preparation) recognized a similar retino-thalamic profile. Specifically, the topography and number of targets in Caretta, as Chrysemys, are most similar to those in Gekko and Iguana. For these species, four retinal targets are identified ventral to a dorsal optic nucleus, the most dorsal being the pars dorsalis of the lateral geniculate nucleus. An additional target - the dorsal central nucleus - occurs dorsal to the dorsal optic nucleus; in lizards, a seventh target - nucleus intercalatus thalami - appears medial to a pars dorsalis. Compared with lizards, the dorsal optic nucleus occupies a relatively greater volume of the lateral thalamus in turtles, expecially Caretta.

The number of retinal targets in reptiles compares with that in birds for which five retinal thalamic targets are recognized (Karten et al. 1973; Repérant 1973b; Micelli et al. 1975). The data suggest that differentiation of the retinal-recipient thalamus into multiple subdivisions characterizes extant members of the sauropsid 
radiation. More specific comparisons between reptiles and birds are precluded by the variation in thalamo-telencephalic pathways (see below) and the small number of reptilian species examined.

\section{Comparisons with Mammals}

Whether thalamic visual nuclei in turtles and birds represent all or part of the lateral geniculate complex of mammals and/or "new" visual nuclei in reptiles and/or birds is debatable. Although HRP experiments demonstrate projections of the visual thalamus to the dorsal pallium of turtles (Hall et al. 1977) and birds (Micelli et al. 1975), the variable pattern of these projections emphasizes the complexities, rather than the simplicities, of a comparison with the retino-geniculostriate pathway of mammals. One nucleus - dorsal optic nucleus of this study - projects to dorsal cortex in turtles (Hall and Ebner 1970b; Hall et al. 1977), four nuclei project to the dorsal pallium (Wulst) of birds (Micelli et al. 1975), while multiple laminae of the dorsal geniculate project to striate and extrastriate cortices in mammals (Holländer and Vanegas 1977). These pathways are ipsilateral in turtles, ipsilateral, contralateral and bilateral in birds, and ipsilateral in mammals.

In summary, it is evident that multiple retinal-recipient targets in the lateral thalamus is a stable pattern among amniote visual systems, while the pattern of thalamofugal pathways is more variable. Additional experimental analyses of these variable patterns may lend insight into the differential involvement of the thalamus and the pallium in central visual mechanisms, and the recognition of visual homologies among amniotes.

Acknowledgements. This work was supported by NIH grants to R.G.N. and NIH postdoctoral fellowship to A.H.B.

\section{References}

Bass AH, Northcutt RG (1975) Retinal projections in the atlantic loggerhead sea turtle, Caretta caretta: An autoradiographic study. Anat Rec 181:308

Bass AH, Northcutt RG (1981) Retinal recipient nuclei in the painted turtle, Chrysemys picta: An autoradiographic and HRP study. J Comp Neurol (In press)

Braford MR Jr, Northcutt RG Retinal projections in Caiman crocodilus. (In preparation)

Butler AB (1974) Retinal projections in the night lizard, Xantusia vigilis Baird. Brain Res 80:116-121

Butler AB, Northcutt RG (1971) Retinal projections in Iguana iguana and Anolis carolinensis. Brain Res 26:1-13

Butler AB, Northcutt RG (1973) Architectonic studies of the diencephalon of Iguana iguana (Linnaeus). J Comp Neurol 149:439-462

Butler AB, Northcutt RG (1978) New thalamic visual nuclei in lizards. Brain Res 149:469-476

Cruce JAF (1974) A cytoarchitectonic study of the diencephalon of the Tegu lizard, Tupinambis nigropunctatus. J Comp Neurol 153:215-238

Cruce JAF, Cruce WLR (1978) Analysis of the visual system in a lizard, Tupinambis nigropunctatus. In: Greenberg N, MacLean PD (eds) Behavior and neurology of lizards. Department of Health, Education and Welfare, pp 79-90

Hall JA, Foster RE, Ebner FF, Hall WC (1977) Visual cortex in a reptile, the turtle (Pseudemys scripta and Chrysemys picta). Brain Res 130:197-216

Hall WC, Ebner FF (1970a) Parallels in the visual afferent projections of the thalamus in the hedgehog (Paraechinus hypomelas) and the turtle (Pseudemys scripta). Brain Behav Evol 3:135-154

Hall WC, Ebner FF (1970b) Thalamotelencephalic projections in the turtle (Pseudemys scripta). J Comp Neurol 140:101-122 
Heacock AM, Agranoff BW (1977) Reutilization of precursor following axonal transport of $\left({ }^{3} \mathrm{H}\right)$ proline-labeled protein. Brain Res 122:143-154

Holländer H, Vanegas $\mathrm{H}$ (1977) The projection from the lateral geniculate nucleus onto the visual cortex in the cat. A quantitative study with horseradish peroxidase. J Comp Neurol 173:519-536

Huber GC, Crosby EC (1926) On thalamic and tectal nuclei and fiber paths in the brain of the American alligator. J Comp Neurol 40:98-224

Karten HJ, Hodos W, Nauta WJH, Revzin AM (1973) Neural connections of the "visual wulst" of the avian telencephalon. Experimental studies in the pigeon (Columba livia) and owl (Speotyto cunicularis). J Comp Neurol 150:253-278

Knapp H, Kang DS (1968a) The visual pathways of the snapping turtle (Chelydra serpentina). Brain Behav Evol 1:19-42

Knapp H, Kang DS (1968b) The retinal projections of the sidenecked turtle (Podocnemis unifilis) with some notes on the possible origin of the pars dorsalis of the lateral geniculate body. Brain Behav Evol $1: 369-404$

Kosareva AA (1967) Projection of optic fibers to visual centers in a turtle (Emys obicularis). J Comp Neurol 130:263-276

Kuhlenbeck H (1931) Über die Grundbestandteile des Zwischenhirnbauplans bei Reptilien. Morph Jhb 66:244-317

Micelli D, Peyrichoux J, Repérant J (1975) The retino-thalamo-hyperstriatal pathway in the pigeon (Columba livia). Brain Res 100:125-131

Northeutt RG, Braford Jr MR, Landreth GE (1974) Retinal projections in the tuatara Sphenodon punctatus: An autoradiographic study. Anat Rec 178:428

Northcutt RG, Butler AB (1974a) Evolution of reptilian visual systems: Retinal projections in a nocturnal lizard, Gekko gecko (Linnaeus). J Comp Neurol 157:453-466

Northcutt RG, Butler AB (1974b) Retinal projections in the Northern water snake Natrix sipedon sipedon (L.). J Morphol 142:117-136

Papez JW (1935) Thalamus of turtles and thalamic evolution. J Comp Neurol 61:433-475

Repérant J (1973a) Les voies et les centres optiques primaires chez la vipère (Vipera aspis). Arch Anat Microsc Morphol Exp 62:323-352

Repérant J (1973b) Nouvelles données sur les projections visueiles chez le Pigeon (Columba livia). J Hirnforsch 14:151-187

Repérant J, Rio J (1976) Retinal projections in Vipera aspis: A reinvestigation using light radioautographic and electron microscopic degeneration techniques. Brain Res 107:603-609

Repérant J, Rio J, Micelli D, Lemire M (1978) A radioautographic study of retinal projections in Type I and Type II lizards. Brain Res 142:401-411.

Senn D (1968) Bau und Ontogenese von Zwischen- und Mittelhirn bei Lacerta sicula (Raffinisque). Acta Anat Suppl 55, 1-150

Senn D (1971) Structure and development of the optic tectum of the snapping turtle (Chelydra serpentina L.). Acta Anat 80:46-57

Accepted March 9, 1981 